\title{
Bioconjugation between CdTe Quantum Dots and a Cationic Protein: An Analytical Method to Determine Protamine in Drug and Urine Samples
}

\author{
Karolayne R. da Costa, ${ }^{a}$ Uéslen Rocha, $^{b}$ Tasso O. Sales ${ }^{b}$ and Josué C. C. Santos ${ }^{\circledR * a}$ \\ ${ }^{a}$ Instituto de Química e Biotecnologia, Universidade Federal de Alagoas, \\ Campus A. C. Simões, 57072-900 Maceió-AL, Brazil \\ ${ }^{b}$ Instituto de Física, Universidade Federal de Alagoas, Campus A. C. Simões, \\ 57072-900 Maceió-AL, Brazil
}

\begin{abstract}
CdTe quantum dots (QD-CdTe) functionalized with mercaptosuccinic acid (MSA) were synthesized in an aqueous medium, varying synthesis time from 0.5 to $4 \mathrm{~h}$. The nanoprobe were characterized by a direct relationship between synthesis time and QD size (2.61-3.04 nm). The QD-CdTe-MSA interacted with protamine (PT), a cationic protein, forming a bioconjugate, thus quenching the photoluminescence intensity and generating an on-off system. The nanoprobe produced at a synthesis time of $1 \mathrm{~h}\left(\mathrm{QD}-\mathrm{CdTe}_{1}\right)$ presented PT's best sensitivity in a succinate buffer $(\mathrm{pH}=5)$. Under the optimized conditions, the proposed method presented a linear range of $0.05-0.5 \mathrm{mg} \mathrm{L}^{-1}(10-100 \mathrm{nM})$, limit of detection (LOD) $0.01 \mathrm{mg} \mathrm{L}^{-1}(2 \mathrm{nM})$, and relative standard deviation $(\mathrm{RSD}) \leq 2.01 \%(\mathrm{n}=10)$. The interaction of the nanoprobe and PT led to aggregation due to a bioconjugate formation. The systems' hydrodynamic radius varied from $4.31 \mathrm{~nm}\left(\mathrm{QD}-\mathrm{CdTe}_{1}\right)$ to $30.50 \mathrm{~nm}$ for the bioconjugate (QD-CdTe $-\mathrm{PT})$. The method was sensitive to variation in ionic strength and based on thermodynamic parameters; it was demonstrated that the interaction mechanism occurred preferentially through electrostatic forces. Finally, the method proved to be fast, sensitive, and viable for quantifying PT in drugs and synthetic urine samples with recoveries above $95 \%$.
\end{abstract}

Keywords: bioconjugation, protamine, nanoprobe, (bio)interaction, quenching

\section{Introduction}

Protamine (PT) is a low molecular weight polycationic protein (from 5000 to $10,000 \mathrm{Da}$ ) whose composition is rich in amino acids such as arginine ( $>67 \%$ ), proline, serine, and valine, and which can be obtained from the sperm of salmon and other fish belonging to the family Salmonidae. ${ }^{1,2}$ This protein can be used for deoxyribonucleic acid (DNA) purification, increase the life span of insulin in the body, and as an antibacterial agent in food. ${ }^{3,4}$ Besides, according to Boer et al., ${ }^{5} \mathrm{PT}$ is the only molecule approved by the Food and Drug Administration (FDA) to act as a neutralizing agent for heparin and is administered during procedures involving extracorporeal circulation, such as dialysis and cardiac surgery. ${ }^{5,6}$ However, if misused, it can cause systemic hypotension, pulmonary hypertension, hemorrhage, sudden pressure drop, bradycardia, and dyspnea. ${ }^{6,7}$ Due to its wide range of applications and

\footnotetext{
*e-mail: josue@iqb.ufal.br, jcarinhanha@yahoo.com.br
}

medicinal importance, it is essential to develop analytical methods for determination and quality control, both in pharmaceutical formulations and biological samples.

PT can be determined by spectrophotometric, ${ }^{8}$ electrochemical, ${ }^{9}$ reverse-phase high-performance liquid chromatography (RP-HPLC) ${ }^{10}$ mass spectrometry (MS), ${ }^{11}$ capillary electrophoreses (CE), ${ }^{12}$ immuno-enzymatic assays (ELISA), ${ }^{13}$ and real-time polymerase chain reaction $(\mathrm{PCR})^{14}$ methods, among others. However, some of these methodologies present limitations, such as lower precision and analytical frequency, the need for sophisticated instrumentation, high operational and maintenance costs, and complex analysis. These limitations make it necessary to develop new quantification methods. Thus, for proteins and other biomolecules, molecular fluorescence spectroscopy emerges as a compelling alternative to investigate both qualitative and quantitative parameters. It presents operational simplicity, high sensitivity, and instrumental selectivity, real-time detection, and is non-destructive. ${ }^{15,16}$ In addition, molecular fluorescence 
spectroscopy allows direct monitoring (or through probes) many photochemical parameters involved in viscosity, mobility, macromolecule orientation, intermolecular distance, locations, and distributions in complex systems, among others. ${ }^{17}$

The development of a stable and selective fluorescent sensor or probe for each analyte requires strategy, study, and planning. It may involve several scientific fields, such as photochemistry, photophysic, supramolecular chemistry, and nanotechnology. ${ }^{18}$ Presenting adjustable emission wavelengths, high photostability, adaptability in their functionalization, high quantum yields, and low toxicity when compared to more widely used organic fluorophores, ${ }^{19}$ quantum dots (QD), due to their unique nanomaterial characteristics and potential for application in various areas, are well recognized in the scientific field. QD are most known for their use as fluorescent nanoprobe to detect and determine biomolecules, metallic species, organic compounds, and even microorganisms. These nanomaterials (QD) are suitable to quantify and monitor a great variety of analytes in biological and environmental samples and pharmaceutical and food analysis as well. QD are also efficient for in vivo and in vitro imaging processes, photodynamic therapy, and as theranostic devices. ${ }^{20-23}$

The QD are generally made up of period II-VI elements (CdSe, CdTe, and CdS, type 1), III-V elements (InP and InAs, type 2), and IV-VI elements (PbSe, type 3). ${ }^{24}$ Among these, CdTe stands out for its ease of synthesis in an aqueous medium, with the possibility of adding a wide variety of functionalizing agents (usually containing thiols), yet without the need for more complicated steps that can affect stability. QD-CdTe presents narrow emission bands from visible emission to the infrared, ${ }^{25}$ making them attractive and versatile for applications in the quantification of organic, ${ }^{26-28}$ inorganic, ${ }^{29-31}$ and biological analytes, ${ }^{32-34}$ for in vivo imaging ${ }^{35,36}$ and drug delivery. ${ }^{37}$ Besides, this nanomaterial, even consisting of some potentially toxic metals, depends on functionalization, present low toxicity in the form of nanoparticles, ${ }^{38-40}$ and may have antiinflammatory, healing, and antioxidant, antifungal, and antibacterial properties. ${ }^{41}$

The development of nanoprobes to quantify or monitor an analyte, especially for in vivo and imaging applications, commonly requires the formation of a bioconjugate to provide better stability, efficiency, and selectivity to the system. The bioconjugation process results from the interaction of the functionalizing agent (peptides or proteins, for example) with the analyte, which can occur from the analyte's adsorption on the surface of the QD through non-polar and/or electrostatic interactions, coordinated binding of the QD with the analyte or vice versa, specific bonds of the antibody-antigen type and formation of covalent bonds. ${ }^{42}$ Thus, the field of possibilities for using QD (such as CdTe), especially as photoluminescent probes, still allow exploring many systems (analytes) and applications.

This way, in this work, the synthesis and spectroscopic characterization of QD-CdTe, functionalized with mercaptosuccinic acid (negatively charged), was thus performed. These allowed a fast, accurate, and highly sensitive quantification of PT (a cationic protein) from a bioconjugate protein-nanoparticle formation. Finally, under the optimized conditions, the interaction mechanism was proposed using different techniques, and the method was applied to both commercial medications and synthetic urine samples.

\section{Experimental}

\section{Reagents and solutions}

The following reagents were purchased from SigmaAldrich (St. Louis, USA) or Merck (Darmstadt, Germany) with a purity of $96 \%$ or more: cadmium chloride $\left(\mathrm{CdCl}_{2}\right)$, trisodium citrate dihydrate $\left(\mathrm{C}_{6} \mathrm{H}_{5} \mathrm{Na}_{3} \mathrm{O}_{7} \cdot 2 \mathrm{H}_{2} \mathrm{O}\right)$, mercaptosuccinic acid (MSA), tellurite sodium $\left(\mathrm{Na}_{2} \mathrm{TeO}_{3}\right)$, sodium borohydride $\left(\mathrm{NaBH}_{4}\right)$, protamine $(\mathrm{PT})$, and succinic acid. The other reagents used presented a minimum purity of $90 \%$ or higher.

The PT stock solution (200 $\mathrm{mg} \mathrm{L}^{-1}$ ) was prepared from direct weighing and subsequent water solubilization. The PT working solutions were prepared by sequential dilution of the stock solution. The Britton-Robinson buffer (10 mM for each reagent) was prepared by mixing boric acid, acetic acid, and phosphoric acid in the pH range of 5 to 11 . When necessary, the $\mathrm{pH}$ was adjusted by adding $\mathrm{NaOH}$ or $1 \mathrm{M} \mathrm{HCl}$. All solutions were prepared with ultrapure water (18.2 M $\Omega \mathrm{cm}$ ) obtained from a Master System MS2000 water purifier (Gehaka, São Paulo, Brazil).

\section{Synthesis of QD-CdTe functionalized with MSA (CdTe-MSA)}

The CdTe quantum dots' synthesis was performed based on Carvalho et al. ${ }^{43}$ with modifications. In this procedure, solutions containing $100 \mu \mathrm{mol}$ of cadmium chloride $\left(\mathrm{CdCl}_{2}\right)$, $765 \mu \mathrm{mol}$ of sodium citrate dihydrate, $100 \mu \mathrm{mol}$ of MSA, and $200 \mu \mathrm{mol}$ of sodium tellurite $\left(\mathrm{Na}_{2} \mathrm{TeO}_{3}\right)$ were prepared (in a total volume of $2 \mathrm{~mL}$, for each reagent), and a mass of sodium borohydride $\left(\mathrm{NaBH}_{4}\right)$ equivalent to $660 \mu \mathrm{mol}$ was weighed. Then, in a round-bottom flask $(50 \mathrm{~mL})$ containing a volume of $17 \mathrm{~mL}$ of ultrapure water and under constant stirring and in a specific order, the $\mathrm{CdCl}_{2}$, sodium 
citrate, $\mathrm{MSA}, \mathrm{Na}_{2} \mathrm{TeO}_{3}$, and sodium borohydride solutions were added. The system was then heated under reflux to $90{ }^{\circ} \mathrm{C}$ and remained at this temperature through different time intervals $(0.5,1,1.5,2$, and $4 \mathrm{~h})$ from the moment of heating. The CdTe-MSA quantum dots (QD-CdTe-MSA) were precipitated with the addition of ethanol and separated/ purified by centrifugation with successive ethanol washes (3 times for $15 \mathrm{~min}$ at $3000 \mathrm{rpm}$ ). Finally, the QD-CdTe-MSA obtained was resuspended in $10 \mathrm{~mL}$ of water and stored at $4{ }^{\circ} \mathrm{C}$, protected from light.

\section{CdTe-MSA spectroscopic characterization}

Absorption spectra in UV-Vis were obtained using a UV-Vis spectrophotometer (model AJX-6100PC, Micronal, São Paulo, Brazil), in the 400 to $600 \mathrm{~nm}$ scanning module using water as reference and $1 \mathrm{~cm}$ quartz cuvettes. Using the parameters obtained by the UV-Vis spectra and through equations 1-3 described in the literature ${ }^{44}$ it was possible to calculate the theoretical size and concentration of the nanoparticles.

$\mathrm{D}=\frac{1.3845-0.00066 \times \lambda}{1-0.00121 \times \lambda}$

$\mathrm{A}_{\lambda}=\varepsilon_{\lambda} \times \mathrm{b} \times \mathrm{C}_{\mathrm{QD}}$

$\varepsilon=10043 \mathrm{D}^{2.12}$

where $\mathrm{D}$ is the size of the CdTe-MSA in nanometers, $\lambda$ (in $\mathrm{nm}$ ) the wavelength of highest absorption, $\mathrm{A}_{\lambda}$ the absorbance value of the QD, $\varepsilon_{\lambda}$ is the molar absorptivity coefficient, $\mathrm{C}_{\mathrm{QD}}$ is the $\mathrm{QD}$ concentration $\left(\mathrm{mol} \mathrm{L}^{-1}\right)$, and $\mathrm{b}$ is the optical path (fixed at $1.0 \mathrm{~cm}$ ).

The emission spectra were obtained using a spectrofluorimeter (RF 5301PC, Shimadzu, Japan), with $1.0 \mathrm{~cm}$ quartz cuvettes, $\lambda_{\mathrm{ex}} / \lambda_{\mathrm{em}}=350 / 523 \mathrm{~nm}$. Dynamic light scattering (DLS) assays were performed using a DLS Microtrac analyzer (OM0003, Microtrac Zetatrac, York, USA). Size distribution analyzes of the nanoparticles for the optimal condition were performed using a Tecnai G2 Spirit Twin (FEI, Hillsboro, USA) transmission electron microscope (TEM) using $\mathrm{LaB}_{6}$ filament and operating at $120 \mathrm{kV}$. The photoluminescence fluorescence lifetime $(\tau)$ measurements were performed using a NanoLogTM fluorimeter (Horiba, Kyoto, Japan) armed with a xenon flash lamp as the excitation source $366 \mathrm{~nm}$. The fluorescence light emitted by the samples was transferred to a monochromator equipped with a diffraction grating (Horiba, 600 grooves $\mathrm{mm}^{-1}$ ) and blaze (at $1000 \mathrm{~nm}$ ) for the selection of wavelengths, and then detected using a photomultiplier detector (model R928P) in the TCSPC (time-correlated single photon counting) configuration.
All the lifetime measurements were performed at room temperature and with the same instrumental parameters. The lifetime curve in the excited state was best adjusted using a monoexponential ${ }^{45}$ curve represented by equation 4 .

$\mathrm{PL}(\mathrm{t})=\mathrm{PL}_{0} \exp \left(-\frac{\mathrm{t}}{\tau}\right)$

$\tau$ refer to lifetime and $\mathrm{PL}(\mathrm{t})$ and $\mathrm{PL}_{0}$ indicate the photoluminescence at a specific time $t$ and at time zero for QD-CdTe ${ }_{1}$, respectively, in the absence and presence of PT.

\section{Determination of protamine using the proposed method}

For the determination of PT and the formation of the bioconjugate with the nanoprobe, QD-CdTe-MSA were used at a final concentration of $500 \mathrm{nM}$, adding different volumes of the standard solution PT samples to obtain cationic protein concentrations from 0.05 to $0.5 \mathrm{mg} \mathrm{L}^{-1}$. The system was completed with a succinate buffer solution ( $25 \mathrm{mM}, \mathrm{pH}$ ) to $2 \mathrm{~mL}$, and after $20 \mathrm{~min}$, the spectrofluorimetric measurements were performed at steady-state mode $\left(\lambda_{\mathrm{ex}} / \lambda_{\mathrm{em}}=350 / 523 \mathrm{~nm}\right.$, a slit of $5 / 3 \mathrm{~nm}$ for $\lambda_{\mathrm{ex}} / \lambda_{\mathrm{em}}$, respectively).

\section{Sample preparation}

PT samples $\left(10 \mathrm{mg} \mathrm{mL}^{-1}\right)$ were obtained from three different commercial suppliers, being then diluted (10,000 times) in ultrapure water for the analysis. The synthetic urine samples were prepared according to differing protocols, varying the chemical composition of each system according to Table S1 (Supplementary Information (SI) section).

\section{Statistical treatment}

The method was optimized based on the analytical curve corresponding to each condition evaluated, with the analytical sensitivity (slope) obtained being an evaluation criterion. For the construction of the analytical curves, at least eight different concentration levels $(n=8)$ were used, based on the following equation:

$$
\left(\frac{\mathrm{PL}_{0}-\mathrm{PL}}{\mathrm{PL}_{0}}\right)=\mathrm{a}_{\mathrm{c}} \times \mathrm{C}_{\mathrm{PT}}+\mathrm{b}
$$

where $\mathrm{a}_{\mathrm{c}}, \mathrm{b}, \mathrm{C}_{\mathrm{PT}}, \mathrm{PL}_{0}$, and PL represent slope, intercept, protamine concentration, and the photoluminescence of the QD-CdTe-MSA, respectively, in PT's absence and presence. For limit of detection (LOD) calculations, $\mathrm{x}_{\mathrm{b}}-3 \mathrm{~s}_{\mathrm{b}}$, 
the ratio was used, where $\mathrm{x}_{\mathrm{b}}$ and $\mathrm{s}_{\mathrm{b}}$ represent the analytical blank's mean and standard deviation $(n=10) .{ }^{46}$ The relative standard deviation ( $\mathrm{RSD}, \mathrm{n}=10$ ) was considered the grouped uncertainty $(\mathrm{S})$ :

$\mathrm{S}_{\left(\mathrm{PL}_{0} / \mathrm{PL}\right)}=\frac{\mathrm{PL}_{0}}{\mathrm{PL}} \times \sqrt{\left(\frac{\mathrm{S}_{(\mathrm{PL})}}{\mathrm{PL}}\right)^{2}+\left(\frac{\mathrm{S}_{\left(\mathrm{PL}_{0}\right)}}{\mathrm{PL}_{0}}\right)^{2}}$

In the process of optimization and validation of the method, when necessary, the results were evaluated using the Student's $t$-test considering normal distribution (random error) and a $95 \%$ confidence interval.

\section{Results and Discussion}

Synthesis and characterization of QD-CdTe functionalized with MSA

Synthesis of QD-CdTe in aqueous media involves the formation of a complex between the metallic cation $\left(\mathrm{Cd}^{2+}\right)$ in solution (equation 7) in the presence of the surface ligand, followed by chemical reduction of tellurium by sodium borohydride (equation 8), and consequent formation of the nanoparticle (equation 9). In this case, mercaptosuccinic acid (MSA, Figure S1a, SI section) binds to the thiol group's cadmium ion. MSA was selected due to its ability

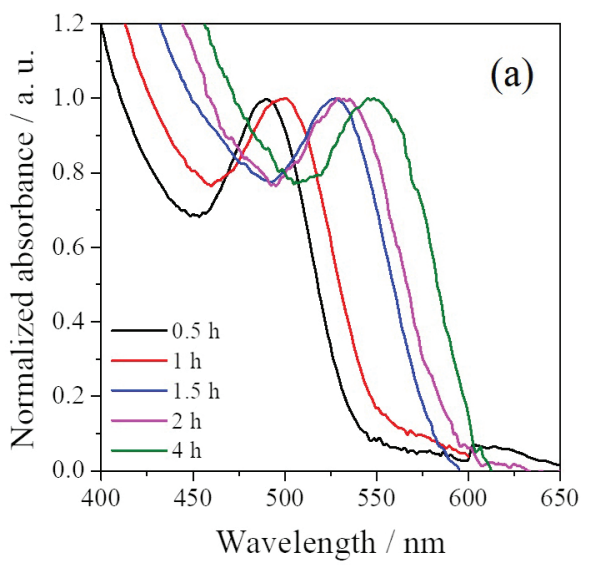

to bind to cadmium via the thiol group and because it has two carboxylic acid groups, giving the nanoparticle two negative charges per mol of ligand (depending on the $\mathrm{pH}$ ), thus leading to greater interaction with the analyte (PT). In turn, sodium citrate was added to the reaction medium to prevent the formation and deposition of $\mathrm{CdTeO}_{3(\mathrm{~s})}{ }^{47}$ Thus, generically, the following reactions occur:

$$
\begin{aligned}
& \mathrm{Cd}^{2+}{ }_{(\mathrm{aq})}+\mathrm{MSA}_{\text {(aq) }} \rightleftharpoons \mathrm{MSA}-\mathrm{Cd}^{2+}{ }_{(\mathrm{aq})} \\
& 4 \mathrm{TeO}_{3}{ }^{2-}{ }_{(\mathrm{aq})}+3 \mathrm{BH}_{4}^{-}{ }_{\text {(aq) }} \rightleftharpoons 4 \mathrm{Te}^{2-}{ }_{(\mathrm{aq})}+3 \mathrm{BO}_{2}^{-}{ }_{(\mathrm{aq})}+6 \mathrm{H}_{2} \mathrm{O}_{(\mathrm{l})} \\
& \mathrm{nMSA}^{2+\mathrm{Cd}^{2+}{ }_{(\mathrm{aq})}+\mathrm{Te}^{2-}{ }_{(\mathrm{aq})}} \rightleftharpoons(\mathrm{CdTe})-\mathrm{MSA}_{\mathrm{n}(\mathrm{aq})}
\end{aligned}
$$

From spectroscopic measurements, the molar extinction and photoluminescence spectra were obtained (Figures 1a-1b). For the systems produced, we observed variation in the molar extinction wavelength of 490 to $548 \mathrm{~nm}$, in photoluminescence of 515 to $573 \mathrm{~nm}$, and particle size from 2.61 to $3.04 \mathrm{~nm}$, respectively from 0.5 to $4 \mathrm{~h}$ of synthesis time (Table 1 ). This profile is due to the nanoparticles' increasing size from the smaller (more unstable) nuclei diffusion process, leading to larger particles' formation. ${ }^{48}$ Therefore, longer synthesis times produce nanoparticles of greater size and less quantum confinement, provoking a gradual displacement to high wavelengths (redshift). ${ }^{49,50}$ This behavior is established for the QD-CdTe and can be confirmed in various studies. ${ }^{51-55}$

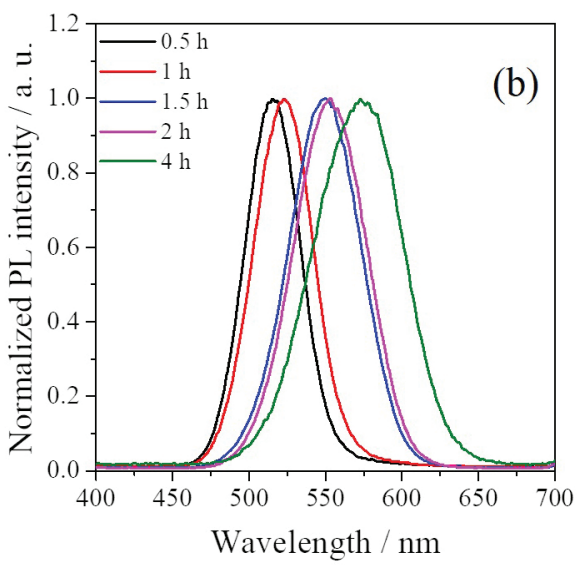

Figure 1. Spectra of (a) molar extinction and (b) photoluminescence for QD-CdTe in an aqueous medium with different synthesis times. Conditions:

\begin{tabular}{|c|c|c|c|c|c|c|c|}
\hline System & time / h & $\lambda_{\text {abs }} / \mathrm{nm}$ & $\lambda_{\mathrm{em}} / \mathrm{nm}$ & Stokes shift / nm & FWHM / nm & Diameter / nm & $\mathrm{C}_{\mathrm{QD}} / \mu \mathrm{M}$ \\
\hline QD-CdTe $_{0.5}$ & 0.5 & 490 & 515 & 25 & 43 & 2.61 & 19.7 \\
\hline QD-CdTe ${ }_{1}$ & 1 & 500 & 523 & 23 & 46 & 2.67 & 13.2 \\
\hline QD-CdTe $_{1.5}$ & 1.5 & 528 & 550 & 22 & 56 & 2.87 & 11.1 \\
\hline QD-CdTe ${ }_{2}$ & 2 & 532 & 553 & 21 & 59 & 2.90 & 11.5 \\
\hline QD-CdTe ${ }_{4}$ & 4 & 548 & 573 & 25 & 67 & 3.04 & 10.7 \\
\hline
\end{tabular}

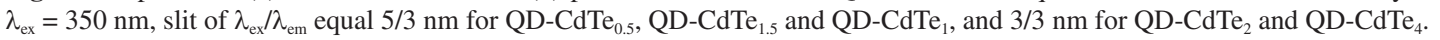

Table 1. Main parameters of the synthesized QD-CdTe

$\lambda_{\text {abs }}$ : maximum absorption wavelength; $\lambda_{\mathrm{em}}$ : maximum emission wavelength; FWHM: width at half height; $\mathrm{C}_{\mathrm{QD}}$ : concentration of $\mathrm{QD}-\mathrm{CdTe}$. 
From the absorption spectra (Figure 1a) and equations 1-3, it was possible to calculate the size and concentration of each synthesized QD (Table 1). Regarding the emission spectra, a proportional relationship between the synthesis time and the value of the total width at half maximum (FWHM) was observed, which varied from 43 to $67 \mathrm{~nm}$. As these nanoparticles' growth does not occur uniformly, the increase in the synthesis time may lead to more significant heterogeneity, making the separation process difficult, leading to a size dispersion in the medium (FWHM > 50)..$^{56}$ In general, the Stokes displacement varied from 21 to $25 \mathrm{~nm}$; this was due to the QD-CdTe size. This parameter can also be influenced by the composition, surface state, nature of the functionalizing agent used, and dark excitons present in the nanoparticle. ${ }^{57-59}$

\section{Evaluation of the QD-CdTe-PT bioconjugate interaction}

In the initial studies, the concentration for all synthesized QD-CdTe (Table 1) was fixed and evaluated as photoluminescence signal intensity for PT. In all cases, there was a reduction in QD-CdTe analytical signal intensity (Figure S2), proving that there was an interaction between the nanoparticle and the cationic protein, possibly an electrostatic interaction. Similar behavior has been observed for carbon dot, ${ }^{60}$ and thioglycolic acid-functionalized QD-CdTe, ${ }^{61}$ wherein both systems suppression of photoluminescence was associated with nanomaterial aggregation. An opposite profile was observed for QD-CdSe functionalized with mercaptopropionic acid (MPA), in which photoluminescence intensity increase was obtained after PT addition. ${ }^{62}$ Therefore, QD-CdTe ${ }_{1}$ and $\mathrm{QD}-\mathrm{CdTe}_{1.5}$ presented the most significant variation in photoluminescent intensity, and for this reason, were selected for optimization.

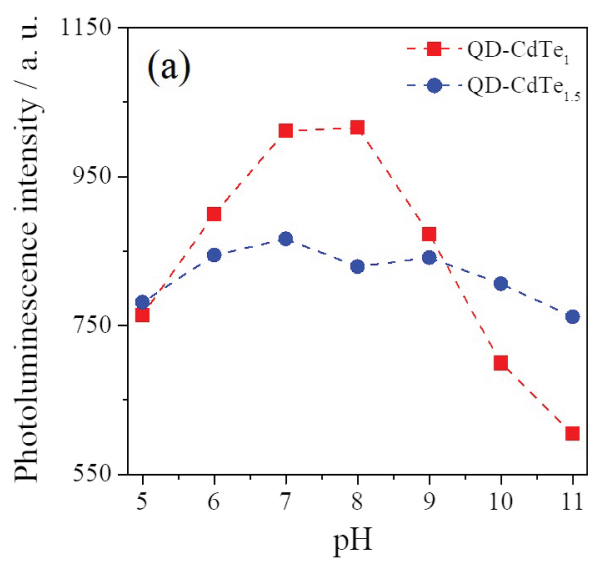

\section{Effect of $\mathrm{pH}$ on the QD-CdTe-PT interaction}

The influence of $\mathrm{pH}$ (5 to 11) on the nanoprobes' photoluminescent intensity was evaluated (Figure 2a). For the QD-CdTe ${ }_{1}$, an increase in signal from $\mathrm{pH} 5$ to 7 was observed, followed by stabilization until $\mathrm{pH} 8$. For values of $\mathrm{pH}<7$, there is more effective protonation of the thiol group (MSA, $\mathrm{p} K_{\mathrm{a} 1}=3.30, \mathrm{p} K_{\mathrm{a} 2}=4.60$ and $\left.\mathrm{p} K_{\mathrm{a} 3}=10.37\right)$, reducing its coordination on the surface of the nanoparticle, destabilizing it; whereas in a basic medium $(\mathrm{pH}>8)$, $\mathrm{Cd}(\mathrm{OH})_{2}\left(\mathrm{~K}_{\mathrm{ps}}=4.5 \times 10^{-15}\right)$ and the respective hydroxy complexes $\left(\mathrm{K}_{\mathrm{f}}=1.95 \times 10^{47}\right)$ may have formed, leading to the degradation of nanomaterial. ${ }^{63} \mathrm{~A}$ different profile was obtained for the QD-CdTe ${ }_{1.5}$ since there was little variation in the intensity of photoluminescence emission with $\mathrm{pH}$ variation, possibly due to nanoparticle size, which avoided the degradation effect.

PT does not present appreciable absorption at the QD-CdTe excitation wavelength $(350 \mathrm{~nm})$ evaluated (Figure S3). This way, evaluating the effect of $\mathrm{pH}$ on the interaction between the nanoprobe and the cationic protein occurred without spectral interference (inner filter effect). In this assay, it was necessary to employ a high amount of cationic protein to promote the reduction of the photoluminescence signal since not all analytical parameters were optimized. In order to assess the optimal $\mathrm{pH}$ of the analysis, the analytical sensitivity was used as an evaluation parameter (Figure 2b). The maximum analytical sensitivity was obtained at $\mathrm{pH} 5$, independent of the QD-CdTe. In an acidic environment, the PT fraction in the protonated form is higher (a positive charge, $\mathrm{pI}=12$ ), which should generate more significant interaction with the negatively charged QD-CdTe, due to preferentially deprotonated MSA. With an increase in $\mathrm{pH}$, a gradual reduction in sensitivity was observed. The $\mathrm{pH}$ values 10 and 11 were not evaluated since no linearity was obtained despite variation in PT concentration.

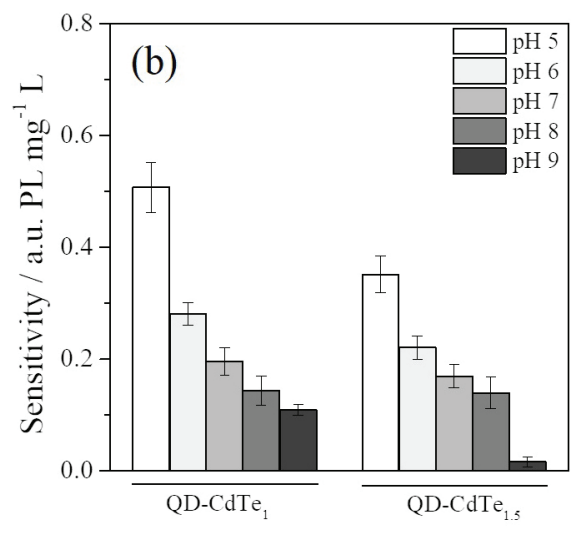

Figure 2. Influence of $\mathrm{pH}$ on the (a) PL intensity of QD-CdTe and (b) analytical sensitivity of QD-CdTe in the presence of PT. Conditions: Britton-Robinson buffer at $10 \mathrm{mM}$, QD-CdTe at $350 \mathrm{nM}, \lambda_{\mathrm{ex}}=350 \mathrm{~nm}$, slit of $\lambda_{\mathrm{ex}} / \lambda_{\mathrm{em}}$ of $1.5 / 5 \mathrm{~nm}$ for QD-CdTe ${ }_{1}$, and $3 / 3 \mathrm{~nm}$ for QD-CdTe 1.5 . 
In general, the method's sensitivity was highest for QD-CdTe ${ }_{1}$, which is related to the nanomaterial size, since less PT would be necessary to interact with the QD-CdTe ${ }_{1}$ surface, attenuating the photoluminescent intensity and thus, increasing the sensitivity of the method. Similarly, Yong et al. ${ }^{64}$ using QD-CdTe functionalized with $\mathrm{N}$-acetylcysteine for quantification of cytochrome c, obtained the most effective photoluminescence suppression with a decrease in nanoparticle size. Therefore, QD-CdTe 1 at $\mathrm{pH} 5$ was selected for further study due to a higher sensitivity to the analyte.

\section{Evaluation of the type and concentration of the buffer solution}

The influence of the buffer system composition on analytical sensitivity was assessed using sodium acetate, ammonium acetate, ammonium citrate, and sodium succinate (Figure 3a). The ammonium acetate system presented the lowest sensitivity, likely associated with the $\mathrm{NH}_{4}{ }^{+}$ion, competing with PT for negative sites on the QD-CdTe ${ }_{1}$ surface, reducing interaction with the analyte, and thus, in high concentrations acting as a potential interferent. Buffer solutions from citric acid ( $\mathrm{p} K_{\mathrm{a} 1}=3.13$; $\mathrm{p} K_{\mathrm{a} 2}=4.76$ and $\mathrm{p} K_{\mathrm{a} 3}=6.40 ; \beta=6.50 \times 10^{-3}$ at $\left.\mathrm{pH} 5\right)$, succinic acid $\left(\mathrm{p} K_{\mathrm{a} 1}=4.21\right.$ and $\mathrm{p} K_{\mathrm{a} 2}=5.72 ; \beta=5.88 \times 10^{-3}$ at $\mathrm{pH} 5)$ and sodium acetate $\left(\mathrm{p} K_{\mathrm{a}}=4.75 ; \beta=5.32 \times 10^{-3}\right.$ at $\mathrm{pH} 5$ ) all presented similar results in terms of sensitivity and buffer index $(\beta)$. The ligands on the surface of QD-CdTe ${ }_{1}$ are in equilibrium with the core; thus, the solvation process reflects ligand-solvent and ligand-ligand interactions, which eventually compete with ligands on the surface.$^{65}$ As the only structural difference between MSA and succinic acid (Figures S1a-S1b) is the presence of the thiol group; this buffer system was selected due to surface ligand similarity.
The effect of buffer solution concentration ( 5 to $100 \mathrm{mM}$ ) was evaluated for the analytical sensitivity of the QD-CdTe 1 -PT system (Figure 3b). An increase in concentration led to an increase in the sensitivity of the method. However, a relationship was observed between the buffer concentration and the measurement uncertainty, possibly associated with the influence on the QD-CdTe $1-\mathrm{PT}$ bioconjugate formation. Therefore, a concentration of $25 \mathrm{mM}$ for the succinate buffer solution was selected for the associated lower error in the procedure and its adequate buffering capacity $\left(\beta=1.47 \times 10^{-2}\right)$.

\section{Evaluation of QD-CdTe ${ }_{1}$ concentration and the ionic strength influence}

The influence of the QD-CdTe ${ }_{1}$ concentration $(250-650 \mathrm{nM})$ on the method's sensitivity was evaluated (Figure S4a). Obviously, for lower concentrations of QD-CdTe ${ }_{1}$, there is a reduction in photoluminescence emission intensity and an increase in sensitivity, requiring less analyte to reduce the analytical signal. Increasing the nanoparticle concentration requires more PT to obtain the same variation in photoluminescence intensity. It was also observed that the FWHM varied from 49 to $52 \mathrm{~nm}$ (for 250-650 nM), and thus it was decided to use an intermediate concentration $(450 \mathrm{nM}, \mathrm{FWHM}=50 \mathrm{~nm})$ for $\mathrm{QD}-\mathrm{CdTe}_{1}$ and ensure high solution stability.

Since the interaction process between QD-CdTe ${ }_{1}$ and PT and the formation of the nanoprobe-protein bioconjugate supposedly involve electrostatic forces, the ionic strength variations' effect changes the medium $(\mathrm{NaCl}$ from 0 to $300 \mathrm{mM}$ ) on the sensitivity of the method was evaluated (Figure S4b). The increase in salt concentration led to a reduction in sensitivity, and after $50 \mathrm{mM}$, the formation of a plateau was observed, without a statistical difference
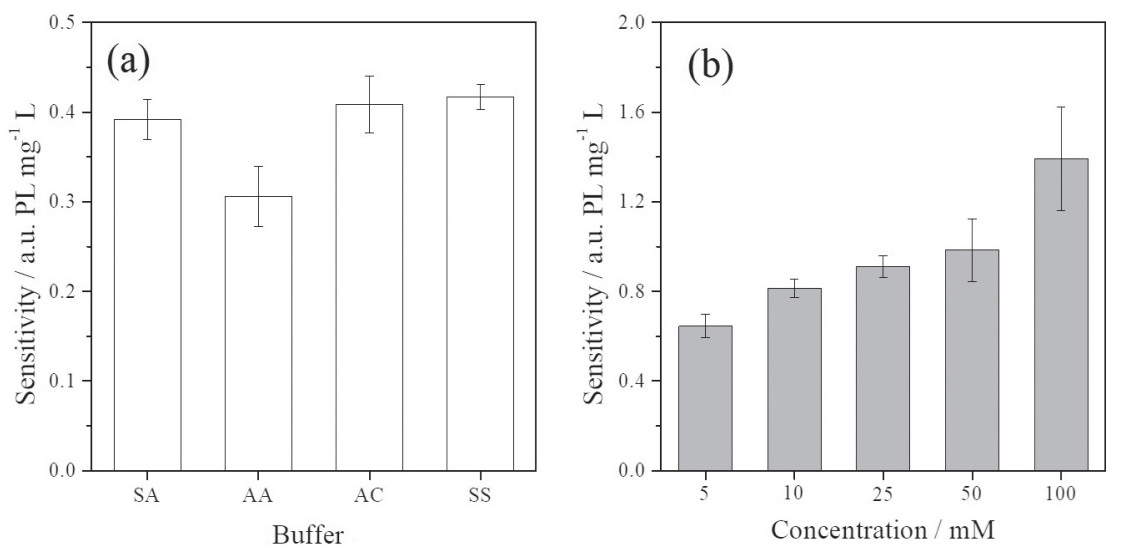

Figure 3. (a) Influence of buffer composition: sodium acetate (SA), ammonium acetate (AA), ammonium citrate (AC), and sodium succinate (SS); and (b) succinate buffer concentration. Conditions: QD-CdTe ${ }_{1}$ at $350 \mathrm{nM}$ and PT from $0.25-2 \mathrm{mg} \mathrm{L}^{-1}(\mathrm{n}=5), \lambda_{\mathrm{ex}} / \lambda_{\mathrm{em}}=350 / 523 \mathrm{~nm}$, slit of $1.5 / 5 \mathrm{~nm}\left(\lambda_{\mathrm{ex}} / \lambda_{\mathrm{em}}\right.$, respectively). 
(analysis of variance (ANOVA) at 95\% confidence, $\left.F_{\text {cal }}=3.69<F_{\text {tab }}=4.07\right)$. Reduction in sensitivity occurred because of the increase in ionic strength due to the reduced activity of species in the environment, leading to a less effective QD-CdTe ${ }_{1}$ and PT interaction. ${ }^{66}$

\section{Evaluation of reaction kinetics and photostability}

The photoluminescence intensity of QD-CdTe in the absence and presence of PT $\left(0.1 \mathrm{mg} \mathrm{L}^{-1}\right)$ up to 60 min (Figure S5a) was evaluated. An increase in the $\left[\left(\mathrm{PL}_{0}-\mathrm{PL}\right) / \mathrm{PL}_{0}\right]$ ratio for up to $20 \mathrm{~min}$ was observed, followed by plateau formation for both evaluated systems. Thus, in subsequent tests, the minimum interaction time was set to $20 \mathrm{~min}$. The nanomaterial photostability in the presence and absence of the protein (Figure S5b) was then characterized using continuous exposure to electromagnetic radiation $\left(\lambda_{\mathrm{ex}}=350 \mathrm{~nm}\right)$. For the QD-CdTe and QD-CdTe 1 -PT systems, the signal variation was around $10 \%$, indicating photostability in the monitored time interval and the evaluated conditions.

\section{Figures of merit of the proposed method}

From the optimized conditions, it was possible to establish the analytical curve for quantifying PT (Figure 4). The main figures of merit were established for the proposed method, which presented an analytical curve $\left[\left(\mathrm{PL}_{0}-\mathrm{PL}\right) / \mathrm{PL}_{0}\right]=0.83( \pm 0.10) \times \mathrm{C}_{\mathrm{PT}}+0.005( \pm 0.002)$, $\mathrm{C}_{\mathrm{PT}}$ : concentration of $\mathrm{PT}$, with linear correlation coefficient, $\mathrm{r}=0.999(\mathrm{n}=8)$ for the linear range from 0.05 to $0.50 \mathrm{mg} \mathrm{L}^{-1}(10-100 \mathrm{nM})$, and a limit of detection (LOD, $\mathrm{n}=10)$ of $0.01 \mathrm{mg} \mathrm{L}^{-1}(2 \mathrm{nM})$. The increase in cationic protein concentration ( $\mathrm{PT}>0.5 \mathrm{mg} \mathrm{L}^{-1}$ ) caused a loss of linearity (Figure 4), with the redshift in the maximum emission wavelength of QD-CdTe $e_{1}$. Finally, the method's precision $(\mathrm{n}=10)$ was proved based on $\mathrm{RSD} \leq 2.01 \%$ $\left(\mathrm{C}_{\mathrm{PT}}=0.15 \mathrm{mg} \mathrm{L}^{-1}\right)$.

The proposed method presented higher sensitivity than traditional methodologies such as liquid chromatography with a diode array detector (DAD, $\lambda=214 \mathrm{~nm}$ ). ${ }^{67}$ Concerning other methods that employ photoluminescent QD nanoparticles to determine PT in medicines and human plasma, such as QD-ZnS doped with $\mathrm{Mn},{ }^{53}$ QD-CdTe-glutathione ${ }^{68}$ and QD-CdS-bovine serum albumin (BSA), ${ }^{69}$ the figures of merit of the proposed method were equivalent. For the other analytical systems reported in the literature, Table S2 summarizes each method's main parameters and general aspects, showing the proposed method's advantages based on the QD-CdTe nanoprobe.

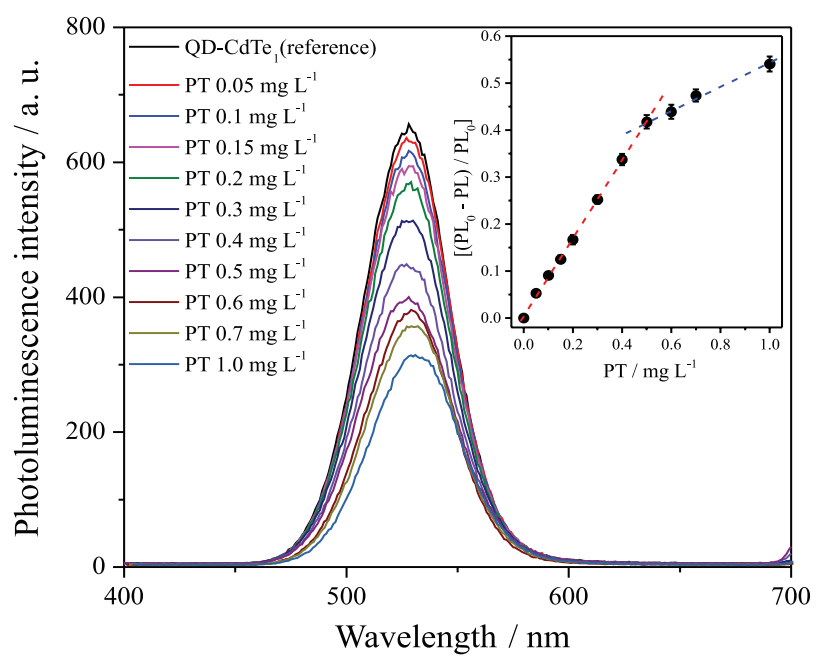

Figure 4. The PL intensity spectral profile of the $\mathrm{QD}_{-\mathrm{CdTe}}$ with increasing PT concentrations and respective analytical curve (plot inset, $\mathrm{n}=3)$. Conditions: succinate buffer solution $(25 \mathrm{mM}$, pH 5), QD-CdTe at $450 \mathrm{nM}, \lambda_{\mathrm{ex}} / \lambda_{\mathrm{em}}=350 / 523 \mathrm{~nm}$ (linear range), slit of $5 / 3 \mathrm{~nm}\left(\lambda_{\mathrm{ex}} / \lambda_{\mathrm{em}}\right.$, respectively).

\section{Mechanism of bioconjugate formation (QD-CdTe, 1 -PT)}

\section{Assessment of nanomaterial aggregation}

Once QD-CdTe $e_{1}$ was functionalized with MSA, at $\mathrm{pH} 5$, the nanoparticle's surface presents a prevalence of negative charges, while PT $(\mathrm{pI}=10-12)$ presents a global positive charge. Thus, it is assumed that bioconjugation between QD-CdTe ${ }_{1}$ and PT occurs, preferably by electrostatic interaction, therefore aggregating nanomaterial and consequently suppressing photoluminescent emission. The aggregation of the QD-CdTe 1 -PT system was evaluated using TEM and DLS experiments.

The surface morphology structure of the produced CD-CdTe ${ }_{1}$ revealed by TEM (Figures S6a-S6b) indicate well dispersed and quasi-spherical nanoparticles presenting a size distribution with an average diameter of $3.10 \pm 1.34 \mathrm{~nm}$ (Figure S6c), similar to that calculated empirically (variation of 16\%) using equation 1 . In the cationic protein presence (bioconjugation), the formation of nanoprobe aggregates was observed (Figure S6d), confirming the proposed mechanism.

The QD-CdTe 1 system presented a hydrodynamic radius of $4.31 \pm 1.12 \mathrm{~nm}$ (Figure 5), which differs from the size calculated empirically (Table 1) and TEM analysis (Figure S6c) since this technique considers all species and interparticle interactions to occur in the medium. ${ }^{70}$ Cationic protein was added to the system (PT 0.2 and $0.4 \mathrm{mg} \mathrm{L}^{-1}$ ); thus, increasing the size to $14.86 \pm 2.34$ and $30.50 \pm 9.26 \mathrm{~nm}$ (Figure 5).

These results indicate that aggregation of the QD-CdTe 1 -PT system occurred, corroborating with the results obtained for TEM. A similar profile was 


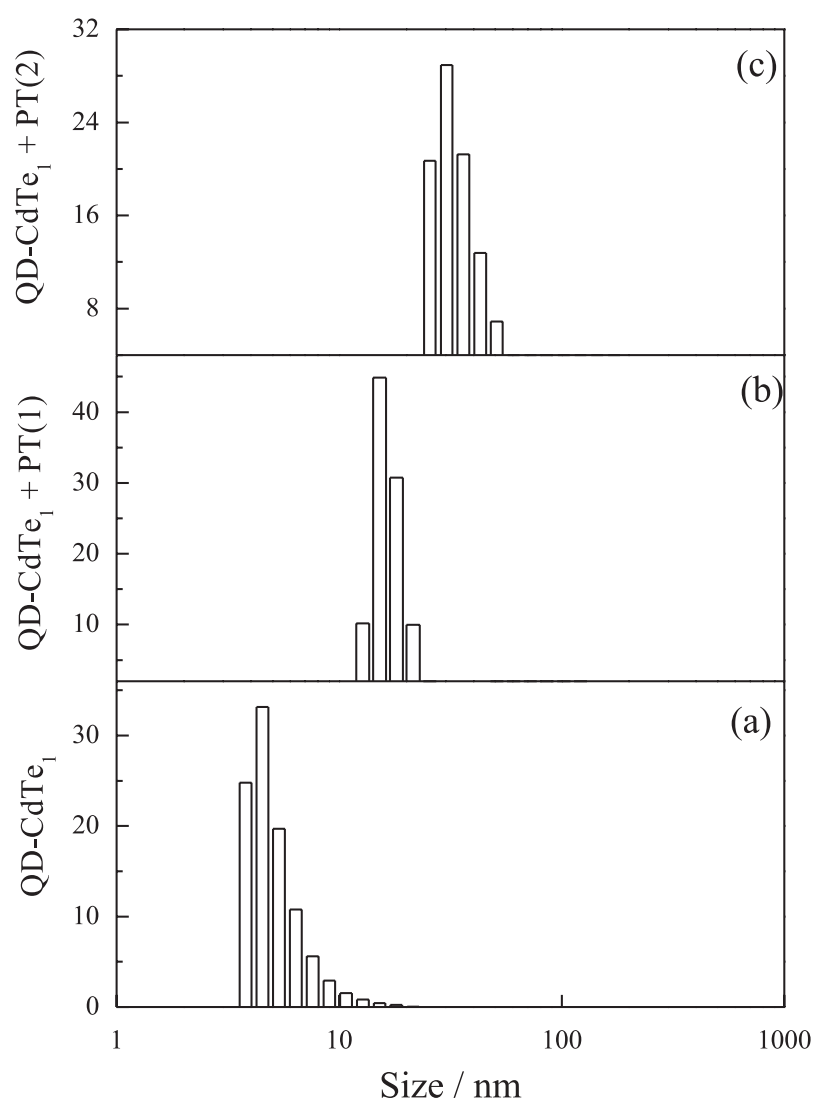

Figure 5. Dynamic light scattering (DLS) profiles of the QD-CdTe (a) without PT, (b) upon the addition of $0.2 \mathrm{mg} \mathrm{L}^{-1}$ of PT, and (c) upon the addition of $0.4 \mathrm{mg} \mathrm{L}^{-1}$ of PT. Condition: succinate buffer solution (25 mM, pH 5) and QD-CdTe ${ }_{1}$ at $450 \mathrm{nM}$.

obtained by Ipe et al. ${ }^{71}$ and Ag et al.,$^{72}$ who found an increase in the hydrodynamic radius of the QD-CdSe and CdTe@CdS-thioglycolic acid (TGA), varying from 9 to $20 \mathrm{~nm}$ and 5.4 to $14.33 \mathrm{~nm}$, after bioconjugation of these with cytochrome P450 (heme protein) and anti-human epidermal growth factor receptor-type 2 (anti-HER2) antibody, respectively.

Type of quenching and thermodynamic parameters determination

Fluorescence quenching is a process characterized by suppressing analytical signal in an analyte presence, preferably static or dynamic quenching. In dynamic quenching, the suppression of fluorescence occurs due to the analyte's collision with the fluorophore in the excited state resulting in its deactivation with non-radioactive energy transfer. Static quenching is characterized through non-fluorescent complex formation between the analyte and fluorophore in the ground state. ${ }^{73}$ The photophysical process nature can be evaluated in function of variation in binding parameters, based on temperature variation ${ }^{74}$ or analysis of the lifetime from the excited state of the probe in the analyte's absence and presence. ${ }^{75}$ By varying the intensity of the QD-CdTe ${ }_{1}$ photoluminescence facing increasing PT concentrations at different temperatures $\left(23\right.$ to $37^{\circ} \mathrm{C}$ ), it was possible to calculate the Stern-Volmer constant (Ksv) and the binding constant $\left(\mathrm{K}_{\mathrm{b}}\right)$, respectively, from equations 10 and 11 (Figures S7a-S7b).

$$
\begin{aligned}
& \left(\frac{\mathrm{PL}_{0}}{\mathrm{PL}}\right)=1+\mathrm{K}_{\mathrm{sv}}[\mathrm{PT}]=1+\tau_{0} \mathrm{k}_{\mathrm{q}}[\mathrm{PT}] \\
& \left(\frac{1}{\mathrm{PL}_{0}-\mathrm{PL}}\right)=\frac{1}{\mathrm{PL}_{0}}+\frac{1}{\mathrm{~K}_{\mathrm{b}} \times \mathrm{PL}_{0}}\left(\frac{1}{[\mathrm{PT}]}\right)
\end{aligned}
$$

where $\mathrm{PL}_{0}$ and $\mathrm{PL}$ respectively correspond to QD$\mathrm{CdTe}_{1}$ photoluminescent intensity in the absence and presence of the analyte. The $\tau_{0}$ and $\mathrm{k}_{\mathrm{q}}$ respectively refer to the half-life and the biomolecular quenching constant. It was also possible to calculate thermodynamic parameters regarding the formation of the QD-CdTe $1-\mathrm{PT}$ bioconjugate (Figure S7c), based on the functions of the state, enthalpy $(\Delta \mathrm{H})$, entropy $(\Delta \mathrm{S})$, and Gibbs free energy $(\Delta \mathrm{G})$ :

$\ln \left(\mathrm{K}_{\mathrm{b}}\right)=\frac{\Delta \mathrm{H}}{\mathrm{R}}\left(\frac{1}{\mathrm{~T}}\right)+\frac{\Delta \mathrm{S}}{\mathrm{R}}$

$\Delta \mathrm{G}=\Delta \mathrm{H}-\mathrm{T} \Delta \mathrm{S}$

where $\mathrm{R}$ and $\mathrm{T}$ respectively correspond to the universal constant of ideal gases and the temperature (K). Table 2 summarizes all of the binding and thermodynamic parameters for the interaction process.

The temperature and Ksv value increased proportionally, this profile being characteristic of dynamic quenching.

\begin{tabular}{|c|c|c|c|c|c|c|c|c|}
\hline \multirow{2}{*}{$\mathrm{T} /{ }^{\circ} \mathrm{C}$} & \multicolumn{3}{|c|}{ Stern-Volmer parameters } & \multicolumn{2}{|c|}{ Binding parameters } & \multicolumn{3}{|c|}{ Thermodynamics parameters } \\
\hline & $\mathrm{Ksv} /\left(10^{7} \mathrm{M}^{-1}\right)$ & $\mathrm{r}$ & $\mathrm{k}_{\mathrm{q}}^{\mathrm{a}} /\left(10^{16} \mathrm{M}^{-1}\right)$ & $\mathrm{K}_{\mathrm{b}} /\left(10^{7} \mathrm{M}^{-1}\right)$ & $\mathrm{r}$ & $\Delta \mathrm{H} /\left(\mathrm{kJ} \mathrm{mol}^{-1}\right)$ & $\Delta \mathrm{S} /\left(\mathrm{J} \mathrm{K} \mathrm{mol}^{-1}\right)$ & $\Delta \mathrm{G} /\left(\mathrm{kJ} \mathrm{mol}^{-1}\right)$ \\
\hline 23 & $1.40 \pm 0.18$ & 0.986 & $1.40 \pm 0.18$ & $1.05 \pm 0.10$ & 0.994 & & & -39.80 \\
\hline 30 & $1.45 \pm 0.12$ & 0.991 & $1.45 \pm 0.12$ & $0.97 \pm 0.08$ & 0.996 & -10.46 & +99.13 & -40.50 \\
\hline 37 & $1.84 \pm 0.16$ & 0.995 & $1.84 \pm 0.16$ & $0.87 \pm 0.07$ & 0.997 & & & -41.19 \\
\hline
\end{tabular}

Table 2. Stern-Volmer constant (Ksv), binding $\left(\mathrm{K}_{\mathrm{b}}\right)$, and thermodynamic parameters of bioconjugate QD-CdTe 1 -PT at different temperatures

${ }^{a} \tau_{0}$ and $\mathrm{k}_{\mathrm{q}}$ (half-life and the biomolecular quenching constant): $10 \mathrm{~ns}$, based on Haro-González et al. ${ }^{76}$ work of QD-CdTe. T: temperature; r: linear correlation coefficient; $\Delta \mathrm{H}$ : enthalpy variation; $\Delta \mathrm{S}$ : entropy variation; $\Delta \mathrm{G}$ : Gibbs free energy variation. 


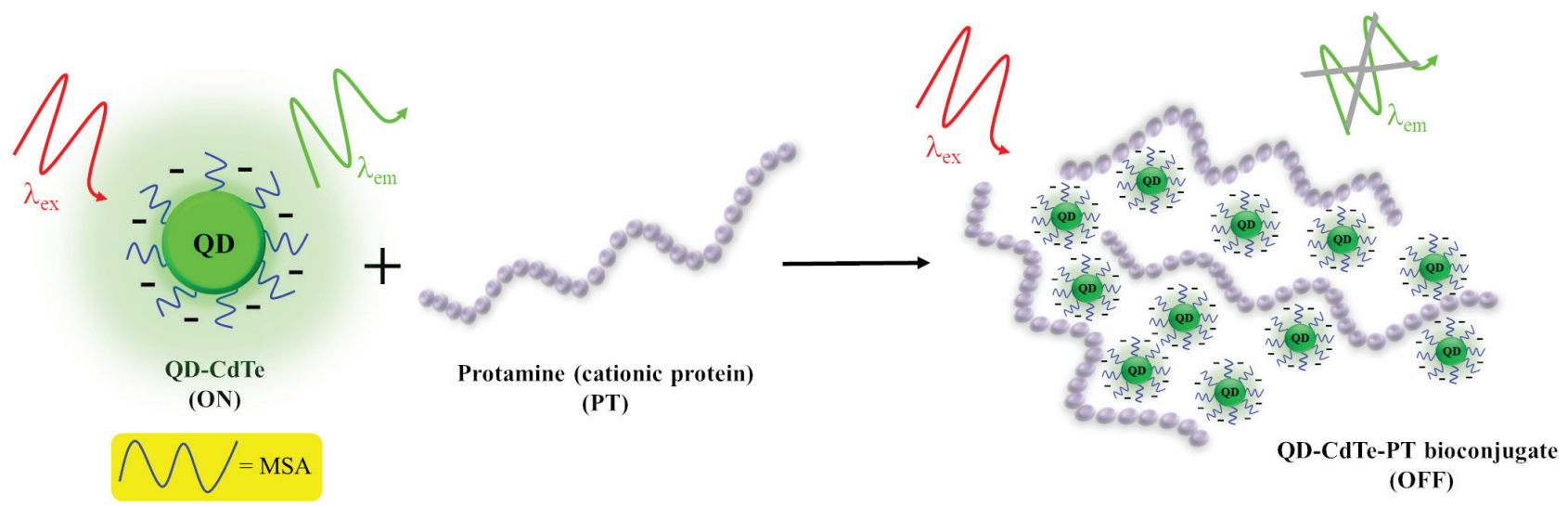

Figure 6. Schematic representation of the photoluminescence quenching mechanism through the PT adsorption process on the surface of QD-CdTe .

However, since the $\mathrm{k}_{\mathrm{q}}$ values (Table 2) are higher than the diffusional biomolecular quenching constant $\left(2.0 \times 10^{10} \mathrm{M}^{-1} \mathrm{~s}^{-1}\right)$, the preferred quenching process is static, leading to the complex formation and corroborating the DLS results for the formation of aggregates. These results were confirmed based on lifetime experiments (Figure S8) since QD-CdTe ${ }_{1}$ presented $29.7 \pm 0.2 \mathrm{~ns}$, while the bioconjugate $\mathrm{CD}-\mathrm{CdTe}_{1}-\mathrm{PT}$ was $28.5 \pm 0.1 \mathrm{~ns}$. The variation of $4.0 \%$ indicates that both systems had a similar lifetime.

The binding constant $\left(\mathrm{K}_{\mathrm{b}}\right)$ indicated a high affinity between QD-CdTe ${ }_{1}$ and PT. It can also be inferred from the thermodynamic parameters that the interaction occurs spontaneously $(\Delta \mathrm{G}<0)$; and is based on electrostatic forces $(\Delta \mathrm{H}<0$ and $\Delta \mathrm{S}>0),{ }^{77}$ according to the initial hypothesis established, and in agreement with the studies evaluating the influence of ionic strength. From the results obtained, it was possible to propose the QD-CdTe ${ }_{1}$ and PT interaction mechanism (Figure 6), considering the cationic protein's adsorption on the nanoparticle surface through electrostatic forces, followed by aggregation of the nanomaterial and thus photoluminescent suppression. Similarly, QD-CdTe systems with glutathione ${ }^{68}$ and QD-CdTe with thioglycolic acid $^{61}$ present similar characteristics, comparable with PT.

\section{Nanoprobe applications in medicine and urine samples}

The applicability of the developed nanoprobe under optimized conditions for the quantification of PT was explored in medication and synthetic urine samples (Tables 3 and 4). In the drug samples, the relative error ranged from -0.70 to $2.60 \%$, which indicates the method's accuracy. After applying the simple Student's $t$-test (Table 3), there was no significant difference between the declared concentrations and those measured (at a 95\% confidence interval).

The different synthetic urine samples (U1-U5) evaluated did not show autofluorescence in the method's optimized
Table 3. Determination of PT in drug samples $(n=3)$ using the proposed method under optimized conditions

\begin{tabular}{lcccc}
\hline Sample & $\begin{array}{c}\text { Proposed } \\
\text { method } / \\
\left(\mathrm{mg} \mathrm{mL}^{-1}\right)\end{array}$ & $\begin{array}{c}\text { Declared } / \\
\left(\mathrm{mg} \mathrm{mL}^{-1}\right)\end{array}$ & Error $/ \%$ & $t^{\mathrm{a}}$ \\
\hline 1 & $9.93 \pm 0.24$ & 10 & -0.70 & 0.50 \\
2 & $10.26 \pm 0.37$ & 10 & +2.60 & 1.22 \\
3 & $10.06 \pm 0.24$ & 10 & +0.60 & 0.43 \\
\hline a Students $t$-test, $t_{\text {tab }}=4.30(v=2)$. & &
\end{tabular}

Table 4. Recovery assays and PT determination in synthetic urine (U1U5) samples with different compositions $(n=3)$

\begin{tabular}{lccc}
\hline Sample & $\begin{array}{c}\text { PT added / } \\
\left(\mathrm{mg} \mathrm{L}^{-1}\right)\end{array}$ & $\begin{array}{c}\text { PT found / } \\
\left(\mathrm{mg} \mathrm{L}^{-1}\right)\end{array}$ & Recovery / \% \\
\hline & 0.00 & $<\mathrm{LOD}$ & - \\
$\mathrm{U} 1$ & 0.40 & $0.40 \pm 0.02$ & 100 \\
& 0.80 & $0.78 \pm 0.03$ & 98 \\
\hline & 0.00 & $<\mathrm{LOD}$ & - \\
$\mathrm{U} 2$ & 0.30 & $0.32 \pm 0.02$ & 107 \\
& 0.60 & $0.58 \pm 0.02$ & 96 \\
\hline & 0.00 & $<\mathrm{LOD}$ & - \\
$\mathrm{U} 3$ & 0.30 & $0.32 \pm 0.02$ & 108 \\
& 0.60 & $0.59 \pm 0.02$ & 98 \\
\hline & 0.00 & $<\mathrm{LOD}$ & - \\
$\mathrm{U} 4$ & 0.30 & $0.30 \pm 0.02$ & 100 \\
& 0.60 & $0.59 \pm 0.02$ & 98 \\
\hline & 0.00 & $<\mathrm{LOD}$ & - \\
U5 & 0.30 & $0.28 \pm 0.01$ & 95 \\
& 0.60 & $0.58 \pm 0.01$ & 96 \\
\hline PT: & & &
\end{tabular}

PT: protamine; LOD: limit of detection.

conditions. Besides, when comparing the QD-CdTe (reference signal) and QD-CdTe1 + urine (U1-U5) systems, the maximum photoluminescence variation in the intensity were less than $3.4 \%$ (Figure S9); therefore, the nanoprobe was considered selective for determining PT in this type of sample. In addition, human serum albumin (HSA, main serum protein, $\mathrm{pI}=4.6$ ), which can be eliminated by urine, 
has a negative global charge on the method's optimal $\mathrm{pH}$; thus, interaction with QD-CdTe ${ }_{1}$ would not be favored. Finally, for samples of synthetic urine with different compositions, recoveries of 95 to $108 \%$ were obtained (Table 4), demonstrating the absence of matrix effects and the proposed method's accuracy. Thus, this methodology proved to be viable for quantifying PT in samples with different levels of complexity.

\section{Conclusions}

In this study, a method for spectrofluorimetric determination of cationic protein was developed based on the bioconjugation process between QD-CdTe ${ }_{1}$ and PT. The proposed method proved to be fast, simple, with good repeatability and simplicity in the optimized conditions. In turn, when applied to samples of medicine and synthetic urine with different degrees of complexity, it presented precision and accuracy in determining PT with high recoveries. This method can thus serve as an alternative for bioanalytical analysis and quality control of cationic proteins such as PT in different types of samples.

\section{Supplementary Information}

Supplementary data are available free of charge at http://jbcs.sbq.org.br as PDF file.

\section{Acknowledgments}

The authors thank the Institute of Chemistry and Biotechnology at the Federal University of Alagoas (UFAL) for encouraging entry into the master's degree of Karolayne R. da Costa. They also acknowledge Coordenação de Aperfeiçoamento de Pessoal de Nível Superior Brazil (CAPES) finance code 001, and Conselho Nacional de Desenvolvimento Científico e Tecnológico (CNPq) for financial support and fellowships (JCCS and UR). Finally, we would like to thank the Transmission Electron Microscopy Laboratory (LabMET) at UFAL and Professor Pedro P. Florez-Rodriguez to carry out the experiments and images by TEM.

\section{References}

1. Akmal, M.; Aulanni'am, A.; Widodo, M. A.; Sumitro, S. B.; Purnomo, B. B.; Widodo, N.; Asian Pac. J. Reprod. 2016, 5, 357.

2. Rodríguez, A. G.; Barcelona, R. R.; Human Protamine Genes' Polymorphisms as a Possible Cause Underlying Male Infertility; Horcajadas, J. A.; Gosálvez, J., eds.; Academic Press: London, United Kingdom, 2018, ch. 6.
3. Castillo, B.; Dasgupta, A.; Klein, K.; Tint, H.; Wahed, A.; Pharmacologic Agents in Transfusion Medicine; Castillo, B.; Dasgupta, A.; Klein, K.; Tint, H.; Wahed, A., eds.; Elsevier: Cambridge, USA, 2018, ch. 11.

4. Potter, R.; Hansen, L. T.; Gill, T. A.; Int. J. Food Microbiol. 2005, 103, 23.

5. Boer, C.; Meesters, M. I.; Veerhoek, D.; Vonk, A. B. A.; Br. J. Anaesth. 2018, 120, 914.

6. Carr, J.; Silverman, N.; J. Cardiovasc. Surg. 1999, 40, 659.

7. Barroso, R. C.; Mendonça, J. T.; Carvalho, M. R.; Costa, R. K.; Santos, J. E.; Braz. J. Cardiovasc. Surg. 2002, 17, 54.

8. Rao, H.; Ge, H.; Wang, X.; Zhang, Z.; Liu, X.; Yang, Y.; Liu, Y.; Liu, W.; Zou, P.; Wang, Y.; Microchim. Acta 2017, 184, 3017.

9. Xiao, K. P.; Kim, B. Y.; Bruening, M. L.; Electroanalysis 2001, 13, 1447.

10. Snycerski, A.; Dudkiewicz-Wilczynska, J.; Tautt, J.; J. Pharm. Biomed. Anal. 1998, 18, 907.

11. Gucinski, A. C.; Boyne, M. T.; Rapid Commun. Mass Spectrom. 2014, 28, 1757.

12. Malý, M.; Křížek, T.; Chromatographia 2016, 79, 1643.

13. Junker, M.; Hobler, H.; Federlin, K.; Immun. Infekt. 1985, 13, 80.

14. Hamad, M. F.; Reprod. Biol. 2019, 19, 6.

15. Kohli, R.; Mittal, K. L.; Developments in Surface Contamination and Cleaning, 12 $2^{\text {nd }}$ ed.; Elsevier: Cambridge, USA, 2019.

16. Jiang, R.; Zhao, S.; Chen, L.; Zhao, M.; Qi, W.; Fu, W.; Hu, L.; Zhang, Y; Int. J. Biol. Macromol. 2019, 156, 1153.

17. Tanaka, T.; Experimental Methods in Polymer Science, $1^{\text {st }} \mathrm{ed}$.; Academic Press: San Diego, USA, 2000.

18. Valeur, B.; Molecular Fluorescence: Principles and Applications, $1^{\text {st }}$ ed.; Wiley-VCH: Weinheim, Germany, 2001.

19. Chandan, H. R.; Schiffman, J. D.; Balakrishna, R. G.; Sens. Actuators, B 2018, 258, 1191.

20. Tian, B.; Al-Jamal, W.; Bossche, J. V.; Kostarelos, K.; Design and Engineering of Multifunctional Quantum Dot-Based Nanoparticles for Simultaneous Therapeutic-Diagnostic Applications; Svenson, S.; Prud' homme, R. K., eds.; Springer Science: New York, USA, 2012, ch. 16.

21. Maitil, A.; Bhattacharyya, S.; Int. J. Chem. Chem. Eng. Syst. 2013, 3, 37.

22. Us, N.; Sunitha, S.; Int. J. Curr. Res. Rev. 2012, 4, 84.

23. Cui, L.; He, X. P.; Chen, G. R.; RSC Adv. 2015, 5, 26644.

24. Onyia, A. I.; Ikeri, H. I.; Nwobodo, A. N.; J. Ovonic Res. 2018 , $14,49$.

25. Rodrigues, S. S. M.; Ribeiro, D. S. M.; Soares, J. X.; Passos, M. L. C.; Saraiva, M. L. M. F. S.; Santos, J. L. M.; Coord. Chem. Rev. 2017, 330, 127.

26. Yu, J.; Wang, X.; Kang, Q.; Li, J.; Shen, D.; Chen, L.; Environ. Sci.: Nano 2017, 4, 493.

27. Xu, S.; Lu, H.; Li, J.; Song, X.; Wang, A.; Chen, L.; Han, S.; ACS Appl. Mater. Interfaces 2013, 5, 8146. 
28. Li, J.; Fu, J.; Yang, Q.; Wang, L.; Wang, X.; Chen, L.; Analyst 2018, 143, 3570.

29. Elmizadeh, H.; Soleimani, M.; Faridbod, F.; Bardajee, G. R.; J. Fluoresc. 2017, 27, 2323.

30. Zhu, J.; Zhao, Z. J.; Li, J. J.; Zhao, J. W.; Spectrochim. Acta, Part A 2017, 177, 140.

31. Qi, J.; Li, B.; Wang, X.; Zhang, Z.; Wang, Z.; Han, J.; Chen, L.; Sens. Actuators, B 2017, 251, 224.

32. Wang, X.; Yu, S.; Liu, W.; Fu, L.; Wang, Y.; Li, J.; Chen, L.; ACS Sens. 2018, 3, 378.

33. Joglekar, S. S.; Gholap, H. M.; Alegaonkar, P. S.; Kale, A. A.; AIMS Mater. Sci. 2017, 4, 209.

34. Shi, F.; Wang, L.; Li, Y.; Zhang, Y.; Su, X.; Sens. Actuators, B 2018, 255, 2733.

35. Khoshkam, M.; Baghdadchi, Y.; Arezumand, R.; Ramazani, A.; Toxicol. Mech. Methods 2018, 28, 539.

36. Li, Y.; Li, Z.; Wang, X.; Liu, F.; Cheng, Y.; Zhang, B.; Shi, D.; Theranostics 2012, 2, 769.

37. Chen, D.; Chen, B.; Yao, F.; Nanoscale Res. Lett. 2018, 13, 373.

38. Kim, J.; Huy, B. T.; Sakthivel, K.; Choi, H. J.; Joo, W. H.; Shin, S. K.; Lee, Y. I.; Sens. Bio-Sens. Res. 2015, 3, 46.

39. Xu, W.; Du, T.; Xu, C.; Han, H.; Liang, J.; Xiao, S.; J. Nanomater. 2015, 2015, ID 583963.

40. Du, Y.; Zhong, Y.; Dong, J.; Qian, C.; Sun, S.; Gao, L.; Yang, D.; RSC Adv. 2019, 9, 12218.

41. Akbari, M.; Rahimi-Nasrabadi, M.; Pourmasud, S.; Eghbali-Arani, M.; Banafshe, H. R.; Ahmadi, F.; Ganjali, M. R.; Nasab, A. S.; Ceram. Int. 2020, 46, 9979.

42. Pereira, G.; Monteiro, C. A. P.; Albuquerque, G. M.; Pereira, M. I. A.; Cabrera, M. P.; Cabral Filho, P. E.; Pereira, G. A. L.; Fontes, A.; Santos, B. S.; J. Braz. Chem. Soc. 2019, 30, 2536.

43. Carvalho, M. S.; Mayrinck, C.; Raphael, E.; Bettini, J.; Ferrari, J. L.; Schiavon, M. A.; J. Braz. Chem. Soc. 2017, 28, 1167.

44. Dagtepe, P.; Chikan, V.; Jasinski, J.; Leppert, V. J.; J. Phys. Chem. C 2007, 111, 14977; Peng, X.; Yu, W. W.; Qu, L.; Guo, W.; Chem. Mater. 2003, 15, 2854.

45. Vaz, R.; Bettini, J.; Júnior, J. G. F.; Lima, E. D. S.; Botero, W. G.; Santos, J. C. C.; Schiavon, M. A.; J. Photochem. Photobiol., A 2017, 346, 502.

46. Khan, S.; Carneiro, L. S. A.; Vianna, M. S.; Romani, E. C.; Aucelio, R. Q.; J. Lumin. 2017, 182, 71.

47. Donoso, J. M. P.; Charles, J. P. M.; Osorio-Roman, I. O.; Guzman, C. C. V.; PAT US9732272B2 2017.

48. Tall, A.; Costa, K. R.; Oliveira, M. J.; Tapsoba, I.; Rocha, U.; Sales, T. O.; Goulart, M. O. F.; Santos, J. C.C.; Talanta 2021, 221, 121545.

49. Girma, W. M.; Fahmi, M.Z.; Permadi, A.; Abate, M. A.; Chang, J. Y.; J. Mater. Chem. B 2017, 5, 6193.

50. Mashinchian, O.; Johari-Ahar, M.; Ghaemi, B.; Rashidi, M.; Barar, J.; Omidi, Y.; BioImpacts 2014, 4, 149.

51. Kim, G. B.; Kim, Y. P.; Theranostics 2012, 2, 127.

52. Zrazhevskiy, P.; Sena, M.; Gao, X.; Chem. Soc. Rev. 2010, 39, 4326.
53. Zhang, Z.; Miao, Y.; Zhang, Q.; Yan, G.; Anal. Biochem. 2015, 478,90 .

54. Veamatahau, A.; Jiang, B.; Seifert, T.; Makuta, S.; Latham, K.; Kanehara, M.; Teranishi, T.; Tachibana, Y.; Phys. Chem. Chem. Phys. 2015, 17, 2850.

55. Cheng, C.; Li, J.; Cheng, X.; J. Lumin. 2017, 188, 252.

56. Qu, L.; Peng, X.; J. Am. Chem. Soc. 2002, 124, 2049.

57. Watanabe, T.; Takahashi, K.; Shimura, K.; Kim, D.; Phys. Rev. B: Condens. Matter Mater. Phys. 2017, 96, 035305.

58. Rakovich, Y.; Walsh, L.; Bradley, L.; Donegan, J. F.; Talapin, D.; Rogach, A.; Eychmueller, A.; Proc. SPIE 2003, 4876, 432.

59. Han, N.; Liu, C.; Zhao, Z.; Zhang, J.; Xie, J.; Han, J.; Jiang, Y.; Int. J. Appl. Glass Sci. 2015, 6, 339.

60. Chen, Y.; Lin, Z.; Miao, C.; Cai, Q.; Li, F.; Zheng, Z.; Lin, X.; Zheng, Y.; Weng, S.; RSC Adv. 2020, 10, 26765.

61. Xue, F.; Liu, L.; Mi, Y.; Han, H.; Liang, J.; RSC Adv. 2016, 13, 10215.

62. Liu, J. X.;Wu, M.X.; Ding, S. N.; Curr.Anal. Chem. 2019, 15, 599.

63. Liu, Q.; Zheng, C.; Zhao, H.; Wang, K.; Tao, W.; Technol. Health Care 2019, 27, 239.

64. Yong, J.; Rongxia, L.; Wenting, A.; Imaging Sci. Photochem. 2014, 32, 181.

65. Grisorio, R.; Quarta, D.; Fiore, A.; Carbone, L.; Suranna, G. P.; Giansante, C.; Nanoscale Adv. 2019, 1, 3639.

66. Burgot, J. L.; Ionic Equilibria in Analytical Chemistry, $1^{\text {st }}$ ed.; Springer-Verlag: New York, USA, 2012.

67. Awotwe-Otoo, D.; Agarabi, C.; Faustino, P. J.; Habib, M. J.; Lee, S.; Khan, M. A.; Shah, R. B.; J. Pharm. Biomed. Anal. 2012, 62, 61 .

68. Ensafi, A. A.; Kazemifard, N.; Rezaei, B.; Biosens. Bioelectron. 2015, 71, 243.

69. Li, H.; Yang, X.; Anal. Methods 2015, 7, 8445.

70. Choudhary, Y. S.; Nageswaran, G.; Sens. Bio-Sens. Res. 2019, 23, 100278.

71. Ipe, B. I.; Shukla, A.; Lu, H.; Zou, B.; Rehage, H.; Niemeyer, C. M.; ChemPhysChem 2006, 7, 1112.

72. Ag, D.; Bongartz, R.; Dogan, L. E.; Seleci, M.; Walter, J. G.; Demirkol, D. O.; Stahl, F.; Ozcelik, S.; Timur, S.; Scheper, T.; Colloids Surf., B 2014, 114, 96.

73. Lakowicz, J. R.; Principles of Fluorescence Spectroscopy, $3^{\text {rd }}$ ed.; Springer: Boston, USA, 2006.

74. Suryawanshi, V. D.; Walekar, L. S.; Gore, A. H.; Anbhule, P. V.; Kolekar, G. B.; J. Pharm. Anal. 2015, 6, 56.

75. Berezin, M. Y.; Achilefu, S.; Chem. Rev. 2010, 110, 2641.

76. Haro-González, P.; Martínez-Maestro, L.; Martín, I. R.; GarcíaSolé, J.; Jaque, D.; Small 2012, 8, 2652.

77. Silva, R. E.; Toledo, K. C. F. T.; Jorge, H. B.; Neto, B. M.; Souza, V. R.; Nakatani, H. S.; Quim. Nova 2014, 37, 1633.

Submitted: August 21, 2020

Published online: February 3, 2021 